\title{
LESIONES QUÍSTICAS TESTICULARES EN LA INFANCIA
}

\author{
J. CALLEJA ESCUDERO, M. PASCUAL SAMANIEGO, M. GARRIDO REDONDO*, \\ V. MATAS GÓMEZ**, L. FERNÁNDEZ DOMÍNGUEZ, E. FERNÁNDEZ DEL BUSTO
}

Servicio de Urología. *Pediatra de EAP. **Servicio de Radiología. Hospital Clínico Universitario. Valladolid.

Actas Urol Esp. 28 (8): 602-605, 2004

\section{RESUMEN}

LESIONES QUÍSTICAS TESTICULARES EN LA INFANCIA

Presentamos el caso de un niño de 11 meses diagnosticado de quiste intratesticular derecho.

Analizamos la etiología, el diagnóstico diferencial y el manejo de las lesiones quísticas testiculares en la infancia. La edad del paciente, la exploración física, los marcadores tumorales y los hallazgos ecográficos contribuyen a la sospecha diagnóstica y en ocasiones al diagnóstico definitivo preoperatoriamente. El diagnóstico diferencial incluye el quiste simple, el quiste epidermoide, los quistes de túnica albuginea, el teratoma testicular, el tumor de células granulosa juvenil-tumor del estroma gonadal, la displasia quística de la rete testis, el linfangioma quístico y la torsión testicular. La enucleación es habitualmente el tratamiento de elección. El conocimiento de las lesiones quísticas testiculares en la infancia permite un adecuado manejo de las mismas y un tratamiento más conservador.

PALABRAS CLAVE: Testículo. Quiste. Infancia.

\section{ABSTRACT}

\section{CYSTIC TESTICULAR LESIONS IN INFANCY}

The present article reports a case 11 month- old infant with a right intratesticular cyst.

We analyze the etiology, differential diagnosis and management off all cystic lesions of the pediatric testis. Patient age at presentation, examination features, tumor markers and sonographic appearance may assist in making a presumptive and occasionally definitive diagnosis preoperatively. The differential diagnosis include intratesticular simple cyst, epidermoid cyst, tunica albuginea cyst, testicular teratoma, juvenil granulosa cell tumor-gonadal stromal tumor, cystic dysplasia of the rete testis, cystic lymphangioma, and testicular torsion Ussually enucleation is the best treatment. A thorough understanding of potentially cystic testis lesions in children leads to the best management choices and often to preservation of a substantial portion of the affected testis.

KEY WORDS: Testis. Cyst. Infancy.

$\mathrm{L}^{\circ}$ os tumores testiculares son raros en la población pediátrica, con una incidencia de 0,5-2 /100.000 niños ${ }^{1}$. La mayoría de las masas testiculares en adultos son malignas, por el contrario, en los niños entre el 31\% y $59 \%$ son benignas ${ }^{2-4}$.
Aunque las lesiones quísticas testiculares no son habituales en la población pediátrica, es importante para el clínico, conocer el manejo de estas lesiones. El diagnóstico de los quistes testiculares suele ser incidental, al ser asintomáticos y no palpables. 


\section{CASO CLÍNICO}

Paciente de 11 meses de edad, sin antecedentes de interés, que consulta por aumento de tamaño del testículo derecho.

La exploración muestra un testículo izquierdo normal y un testículo derecho de consistencia normal, superficie regular y aumentado de tamaño con transiluminación positiva.

Los marcadores tumorales $\alpha$-fetoproteína y $\beta$ HCG fueron normales.

Se solicitó una ecografía testicular, en la que se apreciaba un testículo derecho aumentado de tamaño 2,7 x 1,9 cm con una lesión quística unilocular intratesticular de $1,5 \times 1,8 \mathrm{~cm}$, que presentaba un borde nítido, con una pequeña banda de tejido testicular en la porción anterior y ligeramente mayor en los polos superior e inferior (Fig. 1). Con el análisis doppler, no se observaron vasos en su interior. El testículo izquierdo medía $1,2 \mathrm{~cm}$.

En control ecográfico realizado a los 4 meses (Fig. 2), la lesión quística intratesticular medía $1,2 \mathrm{~cm}$, de características simples y bien definida, por lo que se diagnosticó de quiste testicular simple y se decidió realizar tratamiento expectante con controles ecográficos.

En la ecografía realizada a los 14 meses (Fig. 3), se apreció un engrosamiento de la pared de la imagen quística, con una zona anecoica en su interior de 8,3 mm. Existiendo tejido circundante testicular alrededor de la lesión quística.

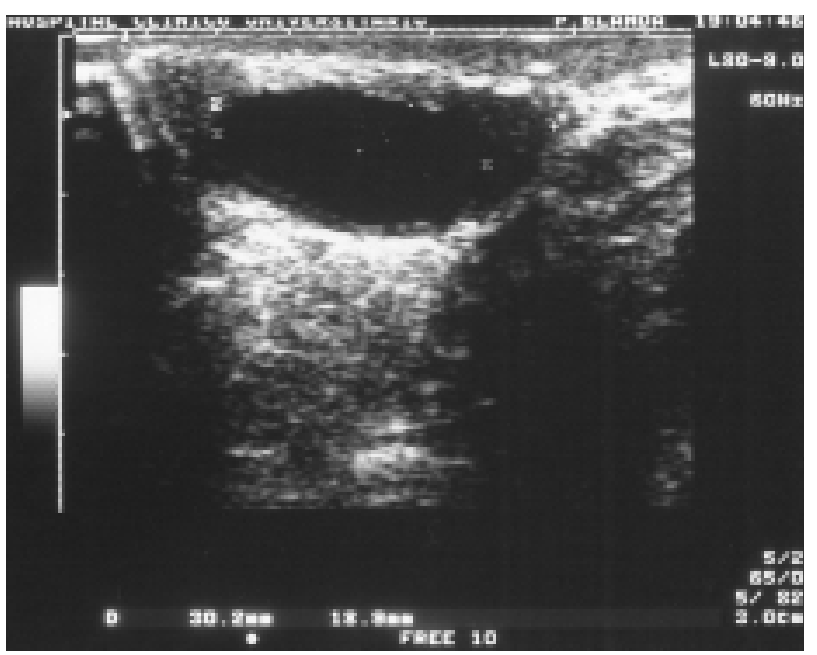

FIGURA 1. Lesión quística unilocular intratesticular de $1,5 \times 1,8 \mathrm{~cm}$, con borde nitido, observando una pequeña banda de tejido testicular.

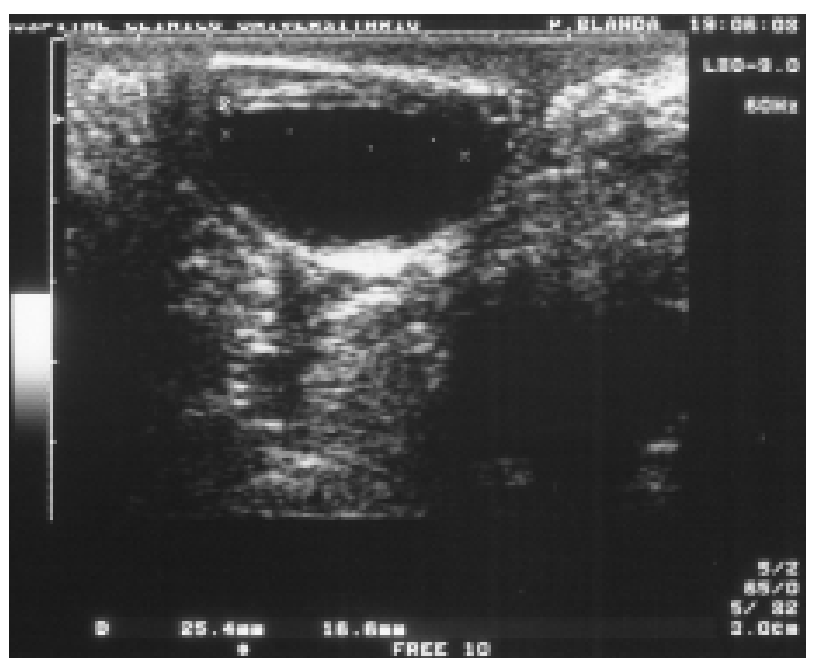

FIGURA 2. Imagen ecográfica a los 4 meses. Lesión quistica intratesticular de $1,6 \mathrm{~cm}$, de caracteristicas simples $y$ bien definida.

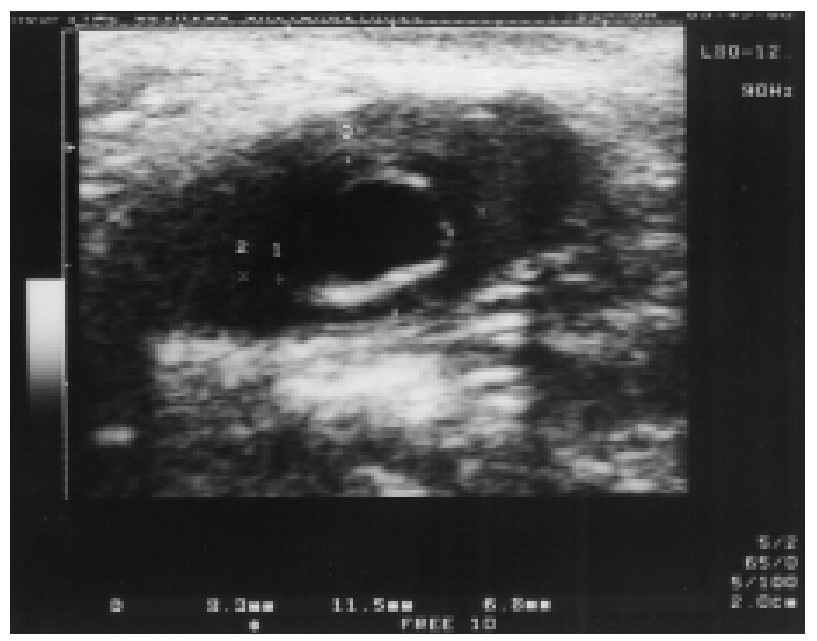

FIGURA 3. Ecografía realizada a los 14 meses. Engrosamiento de la pared quistica, con una zona anecoica en su interior de $8,3 \mathrm{~mm}$.

A los 18 meses, la ecografía testicular fue similar a las previas, con un teste derecho de 2,2 x $1 \mathrm{~cm}$; pero respecto a las anteriores se observó una disminución de tamaño testicular y de la lesión quística, existiendo una pared gruesa e hiperecogénica en su borde interno, así como mayor cantidad de parénquima testicular derecho. Teste izquierdo de $1,6 \times 0,7 \mathrm{~cm}$.

Al apreciar estos cambios en la pared de la lesión quística, se procedió a exploración inguinal bajo anestesia, realizando clampaje del cordón, apertura de la albuginea y exéresis de la tumoración quística. 
La biopsia intraoperatoria fue informada de quiste epidermoide.

En el resultado definitivo de la anatomía patológica, macroscópicamente se apreciaba un nódulo quístico de $1 \mathrm{~cm}$ de diámetro de pared externa lisa y blanca y contenido serohemático. Microscópicamente se observó una formación quística revestida por un epitelio escamoso queratinizante, acumulando abundantes escamas de queratina en su luz, siendo el diagnóstico final de quiste epidermoide.

\section{DISCUSIÓN}

Entre las masas quísticas del interior del escroto podemos encontrar los quistes del epidídimo, del cordón espermático, de la túnica albugínea del testículo y quistes intratesticulares.

Ante la presencia de una lesión quística testicular en un niño, debemos plantear el diagnóstico diferencial entre las siguientes patologías:

- El quiste epidermoide de testículo. Descrito en 1942 por Dockerty y Priestly. Representa menos del 1\% de los tumores testiculares y en ocasiones no se distingue de las neoplasias ${ }^{1}$. Tiene un comportamiento benigno tanto en adultos como en niños. Estas lesiones pueden representar una forma monodérmica benigna de un teratoma. Es muy raro que sean bilaterales. Ecográficamente aparecen como lesiones ovoides bien circunscritas de ecogenicidad variable. Su pared puede ser hipoecoica o hiperecoica. El contenido puede ser anecoico, uniformemente hipoecoico, heterogéneamente hipoecoico o estar formado por anillos concéntricos de hipo e hiperecogenicidad. Este último aspecto da lugar a la imagen típica en "diana” o en "cebolla”. Puede encontrarse calcificación de la pared o del contenido del quiste.

- Quiste dermoide. Es un quiste de inclusión cutánea congénito, en el que tampoco se ha demostrado degeneración maligna. Contiene anejos cutáneos. Es un tumor raro en el testículo, aunque su incidencia real es desconocida, ya que pueden ser clasificados erróneamente como quistes epidermoides o teratomas maduros. Ecográficamente se presenta como una masa sólida con un borde ecogénico y una configuración característica en capas de cebolla, alternando capas hiper e hipoecogénicas ${ }^{5}$. Estos quistes no tienen flujo sanguíneo en el eco-doppler.

Tanto los quistes dermoides como epidermoides unicamente contienen componentes ectodérmicos.

- Teratoma testicular. Representa entre el 10 y el 15\% de los tumores de células germinales en la edad pediátrica y el segundo más frecuente en la infancia. El teratoma maduro contiene componentes derivados de las tres hojas dérmicas, sin evidencia de elementos indiferenciados. Ecográficamente el teratoma quístico aparece como una masa heterogénea, que contiene áreas quísticas y sólidas de distintos tamaños ${ }^{4}$.

- Displasia quística de la rete testis. Es una anomalía congénita benigna que aparece durante el desarrollo testicular y causa múltiples quistes en los túbulos seminíferos. Se produce por la obliteración parcial o completa de los ductos eferentes, causando ectasia y eventualmente transformación quística. Se trata de estructuras líquidas tubulares que remplazan el mediastino testicular $^{6}$. Se asocia con agenesia renal en el 41\%$55 \%$ de los casos $^{7}$.

- Quiste simple testicular. Es raro tanto en la infancia como en los adultos. Se ha observado un aumento de la frecuencia debido al mejor diagnóstico ecográfico. Se localizan más frecuentemente cerca del mediastino testicular. Ecográficamente tiene una pared imperceptible y un centro anecoico, con suave sombra de refuerzo posterior $^{8}$.

- Linfangioma quístico o higroma quístico. Se trata de una malformación de los túbulos seminíferos, caracterizado por un extenso sobrecrecimiento de los vasos linfáticos. Es un tumor benigno de etiología desconocida. Ecográficamente muestra una lesión simple o multiquística con espesor variable de la pared ${ }^{1}$.

- Tumor de células granulosas juvenil- Tumor del estroma gonadal. Supone el 15\% de los tumores del estroma gonadal y el $6 \%$ de los tumores testiculares.

- Otras lesiones quísticas del testículo pueden aparecer en la degeneración quística después de una torsión testicular prenatal. Los quistes de la túnica albugínea suelen aparecer en la $5^{\underline{a}}$ y $6^{\underline{a}}$ década de la vida. 
Las lesiones quísticas suelen manifestarse clínicamente por un aumento de tamaño escrotal en ocasiones acompañado de molestias.

El estudio analítico incluirá marcadores tumorales testiculares, si bien la $\alpha$-fetoproteína puede ser de ayuda limitada en niños menores de un año por una elevación fisiológica de los valores de la misma.

La ecografía es imprescindible en la evaluación de una masa escrotal. La sensibilidad de la ecografía para detectar las masas intratesticulares es mayor del 90\%. Con sondas de alta frecuencia se pueden localizar quistes de 3 e incluso 2 milímetros si están próximos a la albuginea ${ }^{9}$.

$\mathrm{El}$ diagnóstico definitivo de las lesiones quísticas es histológico, excepto el quiste simple testicular, que puede ser identificado preoperatoriamente con ecografía ${ }^{1}$.

Respecto al tratamiento, el teratoma maduro, el quiste dermoide y epidermoide pueden considerarse benignas en la infancia y por lo tanto ser tratadas con enucleación simple ${ }^{10}$. No se ha comunicado ningún caso de metástasis en pacientes prepuberales con teratoma maduro, por lo que no se requiere estudio de extensión. El comportamiento maligno es más frecuente en varones después de la pubertad ${ }^{11}$.

Se ha propuesto un tratamiento conservador para los quistes epidermoides con un seguimiento ecográfico continuado ${ }^{9}$.

En cuanto al tumor de las células granulosas juvenil, la orquiectomía radical es el tratamiento actualmente recomendado ${ }^{12}$.

La displasia quística de la rete testis, y el quiste testicular simple son siempre benignas, por lo que está indicada la observación ${ }^{13}$. No obstante es necesario un seguimiento continuo y ante la presencia de cambios ecográficos ${ }^{14} \mathrm{o}$ la aparición de síntomas, debe ser manejada con cirugía conservadora de testículo, mediante enucleación, por vía escrotal ${ }^{15}$.

\section{REFERENCIAS}

1. Garret JE, Catwright PC, Snow BW, Coffin CM. Cystic testicular lesions in the pediatric population. J Urol 2000;163:928-936.

2. Haas GP, Schumaker BP, Cerny JC. The high incidence of benign testicular tumors. J Urol 1986;136:1219.

3. Belville WD, Insalaco SJ, Dresner ML et al. Benign testis tumors. J Urol 1982;128:1198.

4. Valla JS. Testis sparing surgery for benign testicular tumors in children. J Urol 2001;165:2280-2283.

5. Haas GP, Schumaker BP, Cerny JC. The high incidence of benign testicular tumors in children. J Urol 1986;135:494496.

6. Passarella M, Usta MF, Bivalacqua TJ, Hellstromwig, Davis R. Testicular-sparing surgery: a reasonable option in selected patients with testicular lesions. BJU International 2003;91:337-340.

7. Wojcik LJ, Hansen K, Diamondda et al. Cystic dysplasia of the rete testis: a benign congenital lesion associated with ipsilateral urological anomalies. J Urol 1997;158:600.

8. Dogra VS, Gottlieb RH, Rubensdj, Liao L. Benign intratesticular cystic lesions: US features. RadioGraphics 2001; 21:S273-S281.

9. Calabia de Diego A, López Rasines G, Hernández Rodríguez R, Marco de Lucas E, Lastra García-Barón P, Hernández Castrillo A. Lesiones testiculares que no hay que tocar. Arch Esp Urol 2003;56(3):255-266.

10. Ross JH, Kay R, Elder J. Testis sparing surgery for pediatric epidermoid cysts of the testis. J Urol 1993;149:353.

11. Ciftci AO, Bingöl-Kologlu M, Senocak ME, Tanyel FC, Büyükpamukçu M, Büyükpamukç N. Testiculars tumors in children. J Pediatr Surg 2001;36(12):1796-1801.

12. Chan YF, Restall P, Kimble R. Juvenile granulosa cell tumor of the testis: report of two cases in newborns. J Pediatr Surg 1997;32:752.

13. Noh PH, Cooper CS, Zinder HM. Conservative management of cystic dysplasia of the testis. J Urol 1999;162:2145.

14. Dmochowski RR, Rudy DC, Weitzner S et al. Simple cyst of the testis. J Urol 1989;142:1078.

15. Cassacia G, Spagnoli A, Ferro F. Simple intratesticular cyst in infancy: testis-sparing surgery by scrotal approach. Urology 2000;56:854-855.

Dr. J. Calleja Escudero

C/ Domingo Martínez, 6 - $7^{\circ} \mathrm{B}$

47007 Valladolid

(Trabajo recibido el 1 octubre de 2003) 